\title{
Gastrostomy tube migration causing gastric outlet obstruction and gastric perforation in children - two case reports
}

\author{
Carol Wing Yan Wong^, Patrick Ho Yu Chung \\ Department of Surgery, Li Ka Shing Faculty of Medicine, The University of Hong Kong, Hong Kong, China \\ Correspondence to: Patrick Ho Yu Chung, MBBS, FRCS(Paed), FCSHK, FHKAM. Assistant Professor, Department of Surgery, The University of \\ Hong Kong, Queen Mary Hospital, 102 Pokfulam Road, Hong Kong, China. Email: phychung@hotmail.com.
}

\begin{abstract}
Gastrostomy creation is a common procedure in paediatric surgery. It provides enteral nutrition to patients who cannot achieve adequate nutrition by mouth. Common indications of gastrostomy placement in children include syndromic or neurodevelopmental diseases, severe malformations of the aerodigestive tract, craniofacial abnormalities, and intractable gastroesophageal reflux disease with recurrent aspiration. It is also indicated in patients who suffer from failure to thrive and require extra caloric intake. In contrast to adults, paediatric patients have a weaker ability to complain about problems with their gastrostomy tubes when they occur, in particular when some of these neurological patients are non-communicable. Complications may arise when migration of the catheter goes unnoticed, causing obstruction. Due to the smaller stomach size, thinner gastric wall and narrower gastric outlet in paediatric patients, obstruction from the gastrostomy balloon may result in serious sequelae. Here we present two unusual but serious complications of gastrostomy tubes causing suspected duodenal obstruction and subsequent gastric perforation in paediatric patients, requiring emergency operations. Furthermore, we would like to emphasize the importance of proper gastrostomy tube care and alert the caretakers of the potential sinister complications that can arise. We would also like to take this opportunity to suggest measures to prevent their occurrence.
\end{abstract}

Keywords: Gastrostomy tube; migration; obstruction; perforation; case report

Submitted Apr 07, 2021. Accepted for publication Jun 08, 2021.

doi: $10.21037 /$ tp-21-155

View this article at: https://dx.doi.org/10.21037/tp-21-155

\section{Introduction}

A feeding tube is a device to provide enteral nutrition to patients who cannot obtain adequate nutrition by mouth, or have problems with swallowing. The simplest form of tube feeding is via the nasogastric route. For paediatric patients who require long-term tube feeding, gastrostomy tube has been shown to be better tolerated than nasogastric tube and is associated with an improved quality of life (1). Problems like insertion site infection, leakage, over granulation, bleeding and buried bumper are uncommon and benign (2). Nevertheless, complications may arise when migration of the catheter goes unnoticed, causing obstruction (3-10). We would like to present two unusual but serious complications of gastrostomy tubes causing suspected duodenal obstruction and subsequent gastric perforation in paediatric patients. To the best of our knowledge, this sinister complication from gastrostomy tube has never been reported before. We present the following cases in accordance with the CARE reporting checklist (available at https://dx.doi.org/10.21037/tp-21-155).

\section{Case presentation}

\section{Patient 1}

A 3-year-old boy with laryngomalacia and global

\footnotetext{
^ ORCID: 0000-0001-8723-0594.
} 


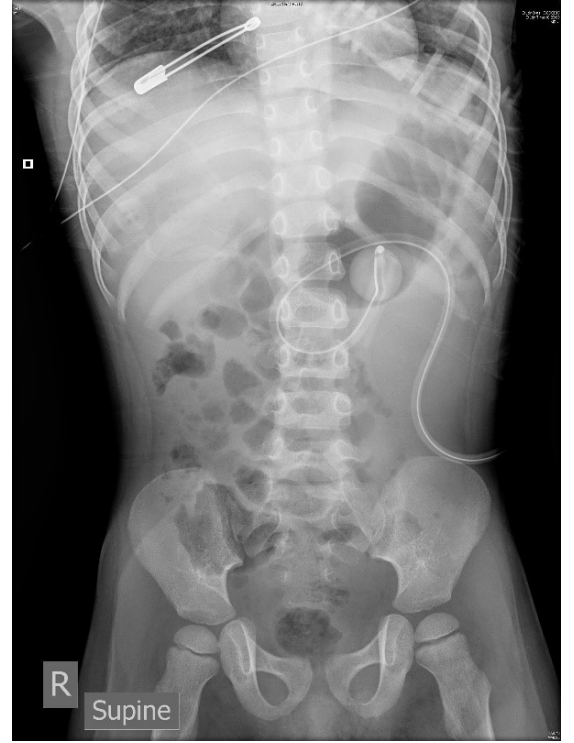

Figure 1 Abdominal X-ray after laparoscopic fundoplication in a patient with previous gastrostomy, showing good position of the Foley catheter balloon inside the stomach.

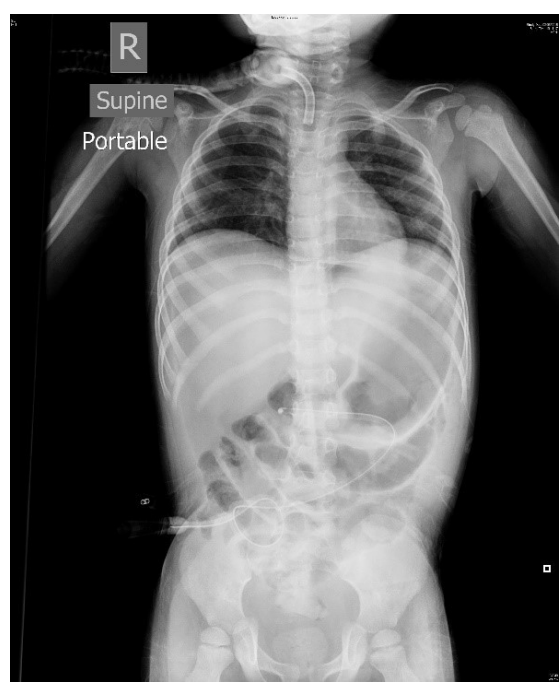

Figure 2 Supine antero-posterior abdominal X-ray showing distal migration of the Foley catheter balloon into the proximal duodenum.

developmental delay was referred to our hospital for gastroesophageal reflux. He was dependent on Bilevel Positive Airway Pressure (BiPAP) ventilation and had a tracheostomy and laparoscopic gastrostomy performed in another hospital in 2013. However, he had persistent vomiting while on gastrostomy feeding and impedance

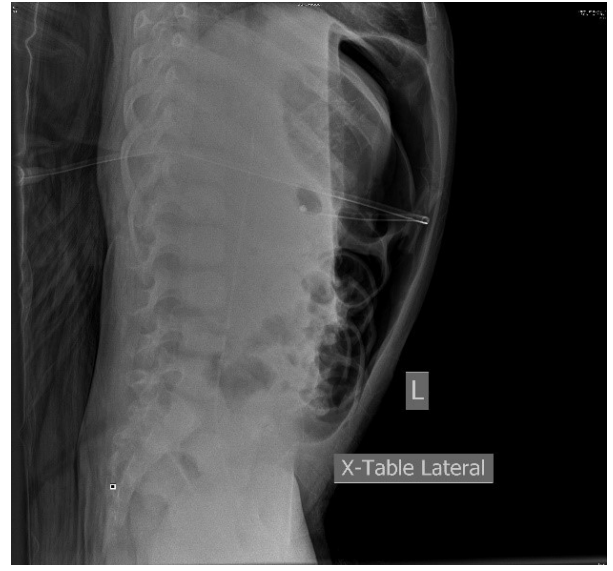

Figure 3 Cross-table lateral abdominal X-ray revealing gross pneumoperitoneum.

study showed evidence of gastroesophageal reflux disease with a DeMeester score of 205. Thus, a laparoscopic fundoplication was performed in May 2015. A Fr 12 Foley catheter was used as a gastrostomy feeding tube postoperatively, in the same manner as pre-operatively. His post-operative X-ray showed good position of the Foley catheter, with the balloon inside the stomach (Figure 1). The post-operative course was uneventful and he was transferred to a rehabilitation hospital. However, the patient developed abdominal distension and peritoneal signs on post-operative day 18. Abdominal X-rays showed free intraperitoneal gas and distal migration of the Foley catheter balloon into the proximal duodenum (Figures 2,3). He was transferred back to our hospital for emergency operation. The gastrostomy tube balloon was deflated and the tube was removed. Laparoscopy revealed straw-coloured peritoneal fluid and a $5 \mathrm{~mm}$ clean perforation at the fundoplication wrap, which was not in close proximity to any of the sutures. Peritoneal lavage and primary suturing of the perforation were performed laparoscopically. He recovered uneventfully after the second operation and a subsequent contrast meal showed no leakage from the stomach. Gastrostomy feeding was tolerated. The parents applied financial aid for purchasing a gastrostomy-button to avoid future complications from gastrostomy tube migration. The timeline of the clinical course is shown in Figure 4.

\section{Patient 2}

Our other patient was an 11-year-old boy with mitochondrial disease, epilepsy, dystonia and mental 


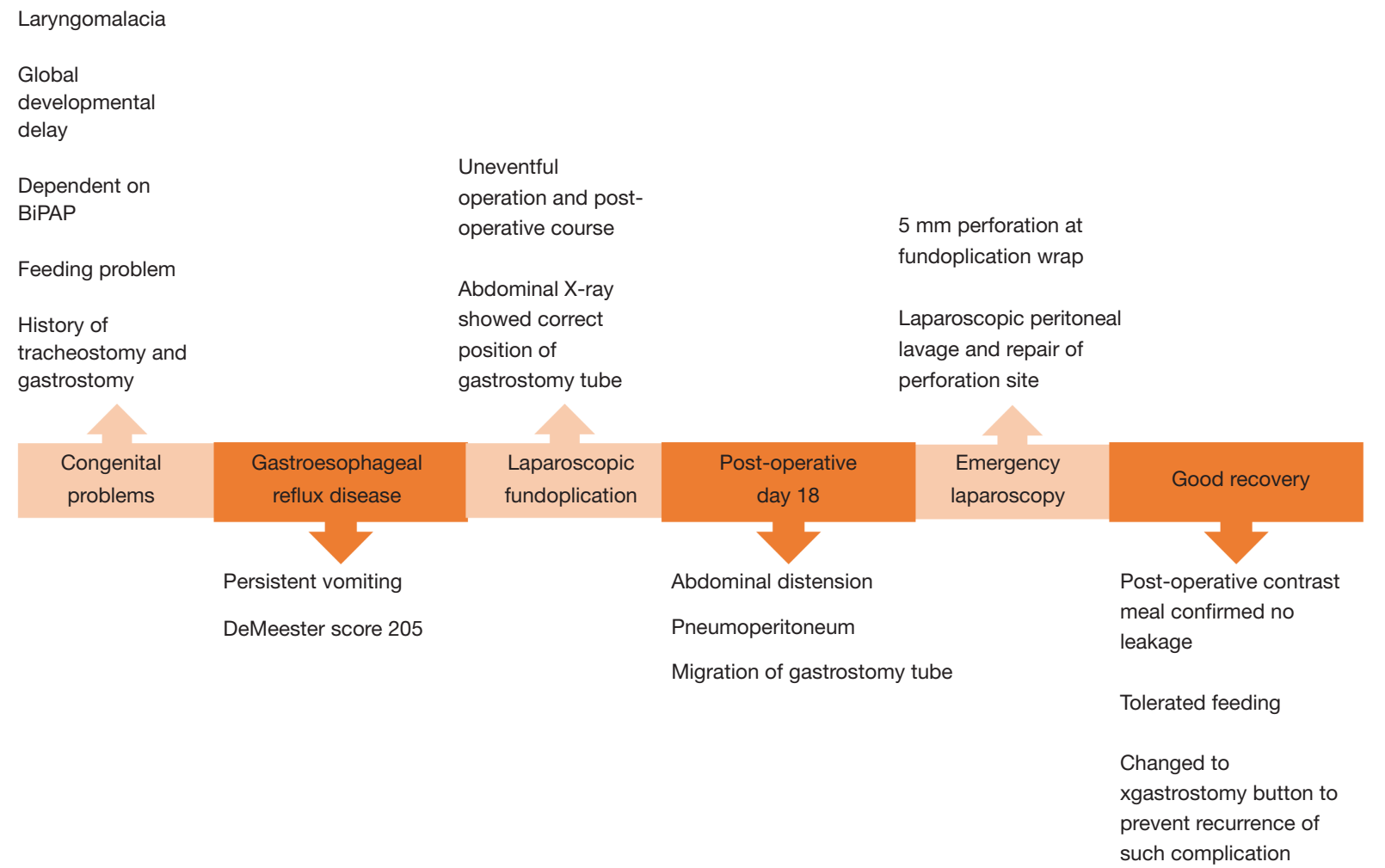

Figure 4 Timeline of clinical course of patient 1.

retardation. He had a history of laparoscopic fundoplication and gastrostomy in 2008 for feeding problem and gastroesophageal reflux disease. A Fr 12 Foley catheter was used as gastrostomy tube all along due to financial difficulties. He was admitted to the intensive care unit of another hospital in Dec 2015 for breakthrough seizure and pneumonia, and was put on BiPAP. He was noted to have gross abdominal distension two days later. Abdominal $\mathrm{X}$-ray showed pneumoperitoneum and suspected distal migration of the Foley catheter balloon (Figure 5). He was transferred to our hospital for emergency operation. We proceeded directly to laparotomy in view of the unstable clinical condition, which revealed turbid peritoneal fluid and moderate amount of adhesions at the left upper quadrant of the abdomen. The old gastrostomy had to be taken down for proper visualization and identification of the pathology. A $2 \mathrm{~cm}$ perforation with clean and healthy edge was found at the fundus (Figure 6). Primary suturing of the perforation was performed and the repair was reinforced with an omental patch. A new Stamm gastrostomy was done. Similarly, this patient had an uneventful recovery and a subsequent contrast meal showed no leakage from the stomach. Gastrostomy feeding was tolerated. The parents accepted our advice in changing to a gastrostomy-button to avoid this complication in the future. The time line of the clinical course is shown in Figure 7.

All procedures performed in studies involving human participants were in accordance with the ethical standards of the institutional and/or national research committee(s) and with the Helsinki Declaration (as revised in 2013). Written informed consent was obtained from the patient.

\section{Discussion}

Common indications of gastrostomy placement in children include syndromic or neurodevelopmental diseases, severe malformations of the aerodigestive tract, craniofacial abnormalities, and intractable gastroesophageal reflux disease with recurrent aspiration. It is also indicated in patients who suffer from failure to thrive and require extra caloric intake from enteral nutrition. There are different approaches in placing a gastrostomy tube $(11,12)$. The Stamm technique (open gastrostomy) was one of the earliest operations for this purpose (13). This technique requires 


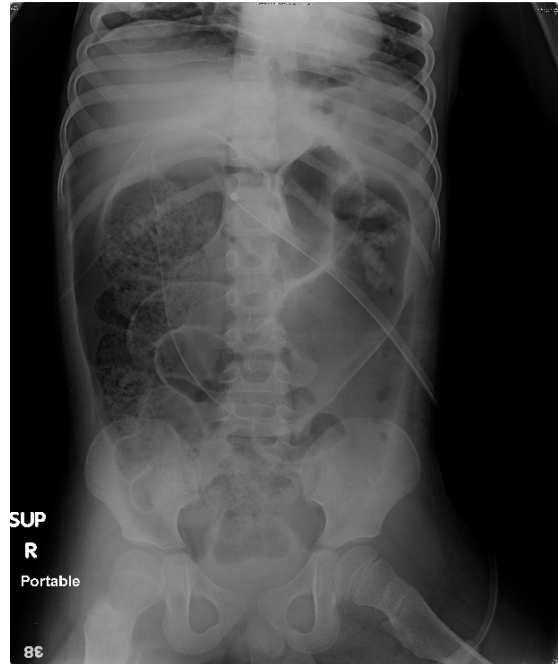

Figure 5 Supine antero-posterior abdominal X-ray showing gross pneumoperitoneum with double wall sign and suspected distal migration of the Foley catheter balloon.

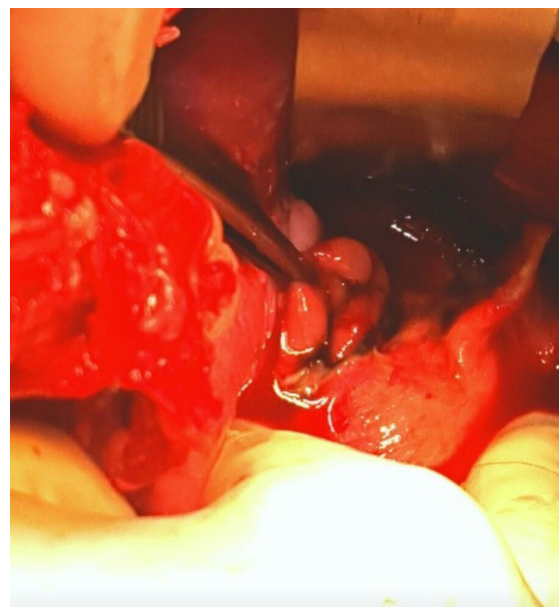

Figure 6 Intraoperative photo of the perforation with clean and healthy edge at the fundus.

an abdominal incision and has gradually been replaced by other minimally invasive approaches. Percutaneous endoscopic gastrostomy (PEG) was described by Gauderer et al. in the 1980s and has become a popular operation due to its minimal invasiveness (14). However, the lack of direct visualization of the abdominal cavity has led to complications such as organ injury and fistulation into the bowel $(15,16)$. In the early 1990s, laparoscopic gastrostomy has been introduced $(17,18)$. It has both the advantages of being minimally invasive and safe (19).
Prior to the surgery, the patient would undergo a 24-hour pH and impedance study to rule out gastroesophageal reflux (20), with a sensitivity of over $80 \%$ (21). Acidic reflux is evident by either a DeMeester score $\geq 14.72$, or $\mathrm{pH}<4$ in one or more of the following: more than $5.5 \%$ of total time; more than $8.3 \%$ of total upright time; or more than $3 \%$ of total supine time (22). Non-acidic reflux is detected by impedance analysis. If concomitant reflux is present, an anti-reflux procedure, namely a laparoscopic fundoplication would be performed concomitantly. The operations of the above two patients were performed laparoscopically (Figure 8). In the standard operation, the anterior stomach wall is anchored to the abdominal wall via two percutaneous stitches. A guidewire is then passed percutaneously into the stomach and serial dilatation up to $16 \mathrm{Fr}$ is performed. After dilatation, a Fr 12 Foley catheter (with the tip cut) is passed into the stomach over the guidewire as a temporary feeding tube with the balloon inflated using the Seldinger technique. The stitches are tied to secure the position of feeding tube. The position of the balloon and absence of leakage of gastric content are confirmed with laparoscopic assessment as well as methylene blue test. A gastrostomy-button cannot be used for primary insertion with this technique. We believe the anchoring stitch together with the balloon would help to prevent distal migration of the catheter. After the wound is stabilized (in about 3 to 4 weeks), the abdominal wall thickness can be measured accurately with a gastrostomybutton measuring device. The family can then order the correct size of gastrostomy button. However, this is a selffinanced item and some families have financial difficulties and could only continue to use a Foley catheter as a substitute.

Complications may arise when migration of the Foley catheter goes unnoticed, causing intestinal obstruction. This has been reported in the adult population, mostly on bedbound elderly, in various case reports (3-8), with only one report on the paediatric population, which was published in 1966 (4). In severe cases, a laparotomy may be required to remove the foreign body $(5,7)$. However, the complication of gastric perforation due to the obstruction was never reported. We postulate that the smaller gastric volume and a thinner gastric wall in the paediatric population render their stomach more susceptible to perforation when high intraluminal pressure develops. Furthermore, after fundoplication, the fundus and oesophagogastric junction are relatively fixed, resulting in less compliance for distension in situations of distal obstruction. Thus, the 


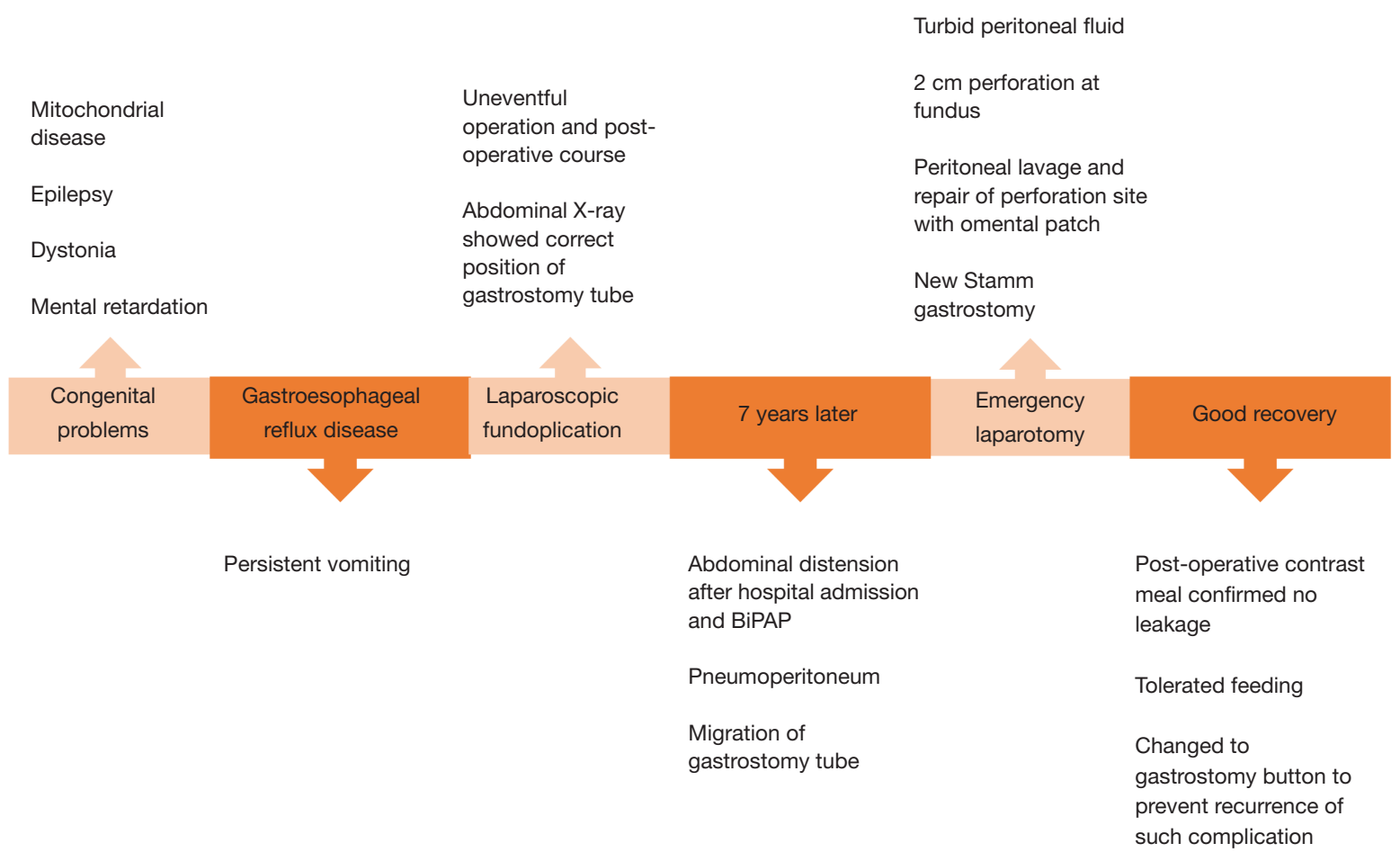

Figure 7 Timeline of clinical course of patient 2.
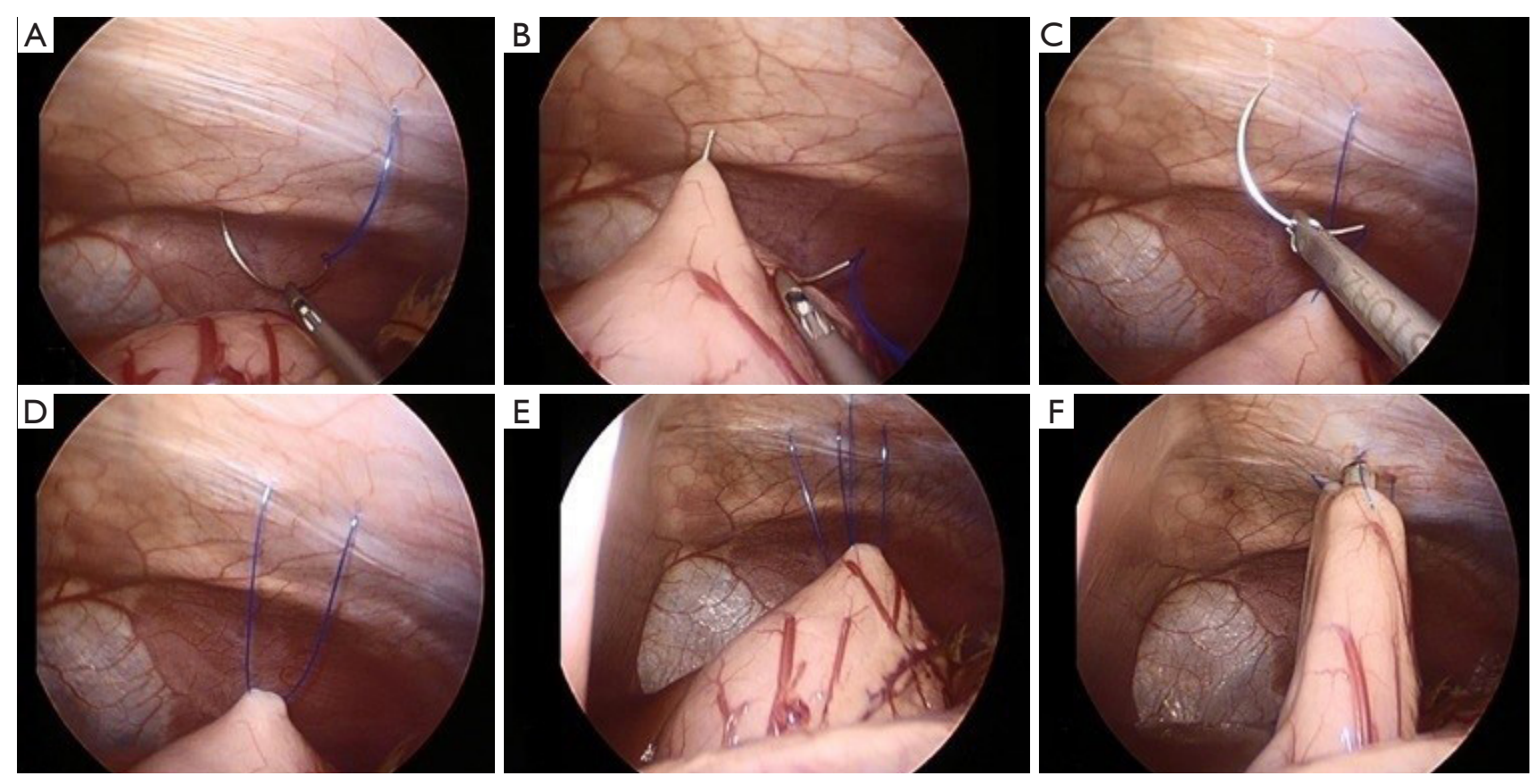

Figure 8 Intra-operative photos showing the key steps of laparoscopic gastrostomy. (A) Percutaneous insertion of the suturing needle; (B) passage of needle through the anterior stomach wall; (C,D) exit of the suturing needle percutaneously; (E) placement of another suture to secure the position of the stomach; (F) passage of gastrostomy tube (Foley catheter) with Seldinger technique. 


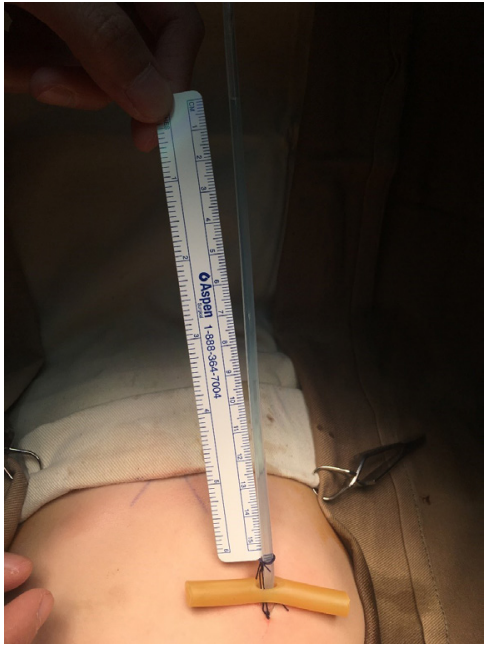

Figure 9 Photo showing an external bumper used to secure the position of the Foley catheter and the measurement of the external length of the gastrostomy tube.

perforations in both our patients occurred at the fundus around the fundoplication wrap, where the intraluminal pressure is highest. In addition, both our patients described above were dependent on BiPAP when the perforation occurred. The inevitable aerophagia resulting from the non-invasive mechanical ventilation would also contribute to the high pressure in the stomach in the situation of gastric outlet obstruction. This explained why the 11-yearold boy in the second case tolerated the gastrostomy tube well for 8 years since the gastrostomy operation, but only developed the complication recently when he required BiPAP for pneumonia. Frequent aspiration of gas from the gastrostomy tube and stringent monitoring of abdominal distension and external length of the tube are essential in these patients.

In order to minimize the possibility of gastrostomy tube migration, as a routine, an external bumper is used to secure the position of the catheter and the external length of the tube is measured before each feed (Figure 9). Aspiration of gastric content including fluid and gas is performed prior to each feed, especially in aerophagic patients and those on non-invasive mechanical ventilation. The Foley catheter is changed to a gastrostomy-button once the stoma is stable. However, the problem lies in the fact that this is a selffinanced item and some families have financial difficulties in affording it. We report the above patients in order to alert caretakers of patients with gastrostomy tubes about the possible risks in tube migration, especially in young children.

\section{Patient perspective}

The parents of the patients in the above case reports understood the possible risks and complications from a gastrostomy tube. Hence, they agreed to change to gastrostomy button to prevent recurrence of such unfortunate incident. However, gastrostomy button was a self-financed item and they would need to pay for it themselves.

\section{Acknowledgments}

Funding: None.

\section{Footnote}

Reporting Checklist: The authors have completed the CARE reporting checklist. Available at https://dx.doi. org/10.21037/tp-21-155

Peer Review File: Available at https://dx.doi.org/10.21037/ tp-21-155

Conflicts of Interest: Both authors have completed the ICMJE uniform disclosure form (available at https://dx.doi. org/10.21037/tp-21-155). PHYC serves as an unpaid editorial board member of Translational Pediatrics from Aug 2020 to Jul 2022. The authors have no other conflicts of interest to declare.

Ethical Statement: The authors are accountable for all aspects of the work in ensuring that questions related to the accuracy or integrity of any part of the work are appropriately investigated and resolved. All procedures performed in studies involving human participants were in accordance with the ethical standards of the institutional and/or national research committee(s) and with the Helsinki Declaration (as revised in 2013). Written informed consent was obtained from the patient.

Open Access Statement: This is an Open Access article distributed in accordance with the Creative Commons Attribution-NonCommercial-NoDerivs 4.0 International License (CC BY-NC-ND 4.0), which permits the noncommercial replication and distribution of the article with the strict proviso that no changes or edits are made and the original work is properly cited (including links to both the formal publication through the relevant DOI and the license). 
See: https://creativecommons.org/licenses/by-nc-nd/4.0/.

\section{References}

1. Pemberton J, Frankfurter C, Bailey K, et al. Gastrostomy matters--the impact of pediatric surgery on caregiver quality of life. J Pediatr Surg 2013;48:963-70.

2. Clarke E, Pitts N, Latchford A, et al. A large prospective audit of morbidity and mortality associated with feeding gastrostomies in the community. Clin Nutr 2017;36:485-90.

3. Barosa R, Santos C, Fonseca J. Gastric outlet obstruction: An unusual adverse event of percutaneous endoscopic gastrostomy. Rev Esp Enferm Dig 2016;108:53-4.

4. Fonkalsrud EW. Intestinal obstruction from gastrostomy tube in infants. J Pediatr 1966;69:809-11.

5. Kamar M, Bar-Dayan A, Zmora O, et al. Small bowel obstruction from a dislodged feeding tube. Age Ageing 2004;33:81-2.

6. McGovern R, Barkin JS, Goldberg RI, et al. Duodenal obstruction: a complication of percutaneous endoscopic gastrostomy tube migration. Am J Gastroenterol 1990;85:1037-8.

7. Nevler A, Zilberman M. Small bowel obstruction in a woman with a missing percutaneous endoscopic gastrostomy tube. Emerg Med J 2014;31:1030.

8. O'Keefe KP, Dula DJ, Varano V. Duodenal obstruction by a nondeflating Foley catheter gastrostomy tube. Ann Emerg Med 1990;19:1454-7.

9. Shah AM, Shah N, DePasquale JR. Replacement gastrostomy tube causing acute pancreatitis: case series with review of literature. JOP 2012;13:54-7.

10. Tibbitts GM, Sorrell RJ. Duodenal obstruction from a gastric feeding tube. N Engl J Med 1999;340:970-1.

11. Sulkowski JP, De Roo AC, Nielsen J, et al. A comparison of pediatric gastrostomy tube placement techniques. Pediatr Surg Int 2016;32:269-75.

12. Angsten G, Danielson J, Kassa AM, et al. Outcome of laparoscopic versus open gastrostomy in children. Pediatr Surg Int 2015;31:1067-72.

13. Stamm M. Gastrostomy by a new method. Med News 1894;65:324.

14. Gauderer MW, Ponsky JL, Izant RJ, Jr. Gastrostomy without laparotomy: a percutaneous endoscopic technique. J Pediatr Surg 1980;15:872-5.

15. Fortunato JE, Cuffari C. Outcomes of percutaneous endoscopic gastrostomy in children. Curr Gastroenterol Rep 2011;13:293-9.

16. McCarter TL, Condon SC, Aguilar RC, et al. Randomized prospective trial of early versus delayed feeding after percutaneous endoscopic gastrostomy placement. Am J Gastroenterol 1998;93:419-21.

17. Shallman RW. Laparoscopic percutaneous gastrostomy. Gastrointest Endosc 1991;37:493-4.

18. Edelman DS, Unger SW, Russin DR. Laparoscopic gastrostomy. Surg Laparosc Endosc 1991;1:251-3.

19. Jones VS, La Hei ER, Shun A. Laparoscopic gastrostomy: the preferred method of gastrostomy in children. Pediatr Surg Int 2007;23:1085-9.

20. Lau CT, Carlile AG, Wong KK, et al. The feasibility and efficacy of multi-channel intraluminal impedance monitoring in children. Pediatr Surg Int 2016;32:119-23.

21. Rosen R, Lord C, Nurko S. The sensitivity of multichannel intraluminal impedance and the $\mathrm{pH}$ probe in the evaluation of gastroesophageal reflux in children. Clin Gastroenterol Hepatol 2006;4:167-72.

22. Liu XL, Wong KK. Gastroesophageal reflux disease in children. Hong Kong Med J 2012;18:421-8.
Cite this article as: Wong CWY, Chung PHY. Gastrostomy tube migration causing gastric outlet obstruction and gastric perforation in children-two case reports. Transl Pediatr 2021;10(7):1940-1946. doi: 10.21037/tp-21-155 